\title{
Evaluating the Insecticidal and Fungicidal Efficiency of Acacia nilotica Pods Extract
}

Abbassy, M. M. S. ${ }^{1 *}$, H. Z. Ibrahim ${ }^{1}$ and Mahenaz A. A. Gab Alla ${ }^{2}$

${ }^{1}$ Department of Environmental Studies, Institute of Graduate Studies \& Research, Alexandria

University, Egypt.

${ }^{2}$ Fruit Fly Research Section, Plant Protection Research Institute, Agriculture Research Center, Ministry of Agriculture - Sabahia, Alexandria.

"Correspondence to: Dr. Moustafa M.S. Abbassy, 163 Horreya Avenue, Chatby, P. C. 21526, P. O. Box 832, Institute of Graduate Studies \& Research, Alexandria University, Alexandria, Egypt. Cell Phone: 002-01006778842. E-mail; moustafabbassy@gmail.com

\section{ABSTRACT}

The study aimed to identify the potential of phytochemical constituent's occurrence in the extract of Acacia nilotica pods and assessment of its bioactivity. Chemical and GC-MS analyses of the ethanolic extract and its fractions of pods identified active compounds such as alkaloids, flavonoids, terpenoids, steroids and tannins. Toxicity of extract proved variable toxicity effects for stages of Ceratitis capitata and Bactrocera zonata. The extract constituents have demonstrated that the Ceratitis capitata egg was more susceptible against hatchability than for Bactrocera zonata, and generally, there was ovicidal efficacy noticed for both insects. Also, the essential oil of $A$. nilotica pods was exhibited larvicidal activity for both insects larva at various high concentrations of the tested plant extract. Concerning the adult stage, ethanolic extract of the tested tree pods proved repellent effects and insecticidal toxicity properties causing knockdown against the adults of Ceratitis capitata and Bactrocera zonata. The ethanol extract of A. nilotica shows antifungal activity against plant fungal pathogens; Aspergillus flavus and Sclerotinia sclerotiorum, where the rate of mycelial growth inhibition was increased by increasing the extract concentration. The extract of A. nilotica was found to have promising effects in controlling the investigated pests.

Keywords: Acacia nilotica, Aspergillus flavus, Ceratitis capitata, Bactrocera zonata, GC-MS analysis, Plant extract, Sclerotinia sclerotiorum.

\section{INTRODUCTION}

The deleterious effect of pesticides on human health and environment has necessitated that alternatives be explored which are safe and environmental friendly. The excessive use of pesticides has resulted in accumulation of pesticide residues in the food and fodder besides exercising deleterious effect on the beneficial organisms (Mohan et al., 2011). Some plants contain components that are toxic to pathogens and insects. When extracted from the plant and applied on infested crops, these components are act as alternative for control strategies to reduce dependency on synthetic pesticides. Plants have ability to synthesize aromatic secondary metabolites, like phenols, flavonoids and tannins. The components with phenolic structures were highly active against the pathogen. These groups of compounds show antimicrobial effect and serves as plant defense mechanisms against pathogenic microorganisms (Gurjar et al., 2012).

Acacia nilotica (A. nilotica) is one of about 135 thorny Africa Acacia species. It is naturally wide spread in arid regions of Africa. It is rich in phenolic compounds and has been reported to possess antimicrobial and phytotoxic activities (Mohana et al., 2011). The bark, leaves and pods of the tree also have many medicinal uses in Africa. Seeds and leaves of $A$. nilotica were reported to contain various active ingredient of multiuse. (Edriss et al., 2012).

Insects affect human and environment beings in a number of ways. Flies (Diptera: Tephritidae) are considered the most destructive insect pests of fruit and vegetables in the world. The invasive fruit fly, Ceratitis capitate (Wiedemann), [C. capitate] and the peach fruit fly, Bactrocera zonata (B. zonata), are highly polyphagous tephritid that infests 300 species of fruit and vegetables throughout the world uses the various hosts in its environment, moving from one to another as fruit mature, in addition flies may damage plants by laying eggs in fruits tissues (Cohen and Yuval 2000; Sarwar et al., 2013).
For the other hand Aspergillus fungus is a large genus composed of more than 180 species. An important group of food borne fungi, A. flavus is the main producer of the well-known carcinogenic aflatoxins. The presence of this fungus and aflatoxins is of huge concern in terms of food safety (Perrone et al., 2007). Another important fungal pathogen Sclerotinia sclerotiorum (S. sclerotiorum), is one of the most devastating and soil-borne plant pathogen. The fungus attacks several plant parts and causes stalk rot/ wilt, rot is a major yield-limiting factor and yield losses can reach up to $100 \%$ when the climatic conditions are favorable for the fungus growth (Davar et al., 2013).

Therefore the present study was aimed to evaluate the effect of partially purified fractions of acetone extract of $A$. nilotica on development of C. capitate, B. zonata, $A$. flavus and Sclerotinia sclerotiorum.

\section{MATERIALS AND METHODS}

\section{Preparation of plant extract}

Egyptian tree; Acacia nilotica (A. nilotica), Kingdom of Plantae was evaluated in this study. The fruit pods of this tree were bought randomly in dried form from local markets located at Alexandria Governorate. The $A$. nilotica tree was identified by Department of Horticultural Crops, Agricultural Research Center, Alexandria. Pods extracted and fractionated, then, the extract was subjected for phytochemical analysis tests based on the standard methods provided by Mbatchou et al., (2011).

Fractionation of $\boldsymbol{A}$. nilotica pods crude extract by column chromatography

All solvents (ethanol, n-hexane, ethyl acetate and methanol) were analytical grade $98-99 \%$ - Merck) and the other chemicals; Silica gel (200-400) mesh for chromatography, anhydrous sodium sulfate and phytochemical analysis reagents were purchased from Sigma Chemicals Co. The extract was fractionated using glass chromatographic columns $(50 \mathrm{~cm} \mathrm{~L} / 1 \mathrm{~cm}$ i.d) packed in sequence with $1 \mathrm{~g}$ of anhydrous sodium sulfate, $10 \mathrm{~g}$ 
normal phase silica gel and covered with $1 \mathrm{~g}$ anhydrous sodium sulfate. The column was pre-washed with $25 \mathrm{ml}$ of n-hexane and then, $5 \mathrm{ml}$ of the extract was transferred to the column. Elution was employed a step gradient elution solvent system from low to high polarity viz. 1) n-hexane $100 \%$, 2) n-hexane: Ethyl acetate 50:50\%, 3) n-hexane: ethyl acetate $25: 75 \%, 4)$ ethyl acetate $100 \%, 5$ ) ethyl acetate: methanol 50:50\%, 6) ethyl acetate: methanol $25: 75 \%, 7)$ methanol 100\%. (Jebasingh et al., 2011). The fractions obtained were concentrated to $1 \mathrm{ml}$, and analyzed qualitatively using GC-MS.

\section{Gas Chromatography-Mass Spectrometry (GC-MS)} analysis

The fractions obtained were analyzed using GC-MS under the following optimum operating condition: Capillary column TG5-MS ( $30 * 0.32 \mathrm{~mm} * 0.25 \mu \mathrm{m}$ thickness) was used. Helium used as carrier gas at $1 \mathrm{ml} / \mathrm{min}$, splitless injection mode at $250^{\circ} \mathrm{C}$. Oven temperature program was start at $80^{\circ} \mathrm{C}$ ( 3 min hold) then elevated at $4^{\circ} \mathrm{C} / \mathrm{min}$ to $280^{\circ} \mathrm{C}$ ( 5 min hold). For MS, the mass transfer line temperature was $290^{\circ} \mathrm{C}$, and ion source temperature at $220{ }^{\circ} \mathrm{C}$. The MS was operated in the electron ionization mode with electron energy of $70 \mathrm{eV}$, and quadruple mass analyzer at mass range of 50-500 amu, with solvent delay at $5 \mathrm{~min}$. NIST library-08 was used for compounds identification (in the fractions injected) depending on the mass spectrum of its fragmentation pattern matched with the given library mass spectrum.

Evaluating the Insecticidal and Antifungal activities of $\boldsymbol{A}$. nilotica extract

The bioassay experiments were carried out using the $A$. nilotica extract to study its potential biocidal activity against the tested insects (C. capitata and B. zonata) and fungi (A. flavus and Sclerotinia sclerotiorum).

Insecticidal effects of $\boldsymbol{A}$. nilotica pods extract

To conduct toxicity tests, two pests choice of order of Diptera, Tephritidae family that cause a lot of losses for many economic fruit crops, these pests are Mediterranean fruit fly; Ceratitis capitata (C. capitata) and peach fruit fly; Bactrocera zonata (B. zonata). Pupae of the two pests were obtained from the Department of Lesions Horticultural Crops - Plant Protection Institute Agricultural Research Center - Giza, Egypt. Wild flies (pupae of C. capitata or B. zonata) were collected from infested citrus fruit fields and kept in separate adult cages till eclosion. The old strain of flies was maintained under optimum laboratory conditions before the toxicity assessment experiments as illustrated by Mahmoud (2014). Eggs, larvae, and adult stages of both $C$. capitata and $B$. zonata, were divided into five groups in addition to control group, each consisting of 10 eggs or larvae or adult (flies). Three replicates were performed for each treatment of egg stage of $C$. capitata and B. zonata at concentrations of $0,200,400,700,800$ and $1000 \mathrm{ppm}$ of acetone extract. Larvae of both the tested insects extract at concentrations of $0,200,300,500,750$ and $1000 \mathrm{ppm}$ of acetone extract. Six groups of adult flies were treated with $0,100,200,300,400$ and $500 \mathrm{ppm}$ of acetone extract. Egg, larva and adults mortality percentages were observed with time and corrected for control mortality for estimation of the mortality percentages.

Fungicidal effect of $\boldsymbol{A}$. nilotica extract

The phytopathogenic fungi used in this experiment were Aspergillus flavus (A. flavus) and Sclerotinia sclerotiorum (S. sclerotiorum), were obtained from the postharvest infected guava and orange fruits showing typical decline symptoms. The fungus strains were selected for their implication in the contamination and the deterioration of the foodstuffs by production of mycotoxins. The collected fungi were identified by the Plant Pathology Department, Plant Protection Research Institute, Agricultural Research Center, Alexandria. Both of $A$. flavus and S. sclerotiorum colony fungus were prepared as described by the method of Javeria et al., (2014). Mycelium was isolated in the form of small sections $(5 \mathrm{~mm}$ in diameter) from infected host tissue of orange and guava separately, incubated at $25 \pm 1^{\circ} \mathrm{C}$ for 7 to 10 days under sterilized conditions in petri dishes contain potato-dextrose agar (PDA) media. Mycelium disc of $A$. flavus or $S$. sclerotiorum was treated with different concentrations of extract $(100,250,500,750$ and 1000 ppm). The treated and control petri plates were inoculated for $7-10$ days at $25 \pm 1^{\circ} \mathrm{C}$. On the other side, Antifungal effect of $A$. nilotica extract against mycelial growth of $A$. flavus or $S$. sclerotiorum was evaluated through the disc diffusion method compared to inhibition growth of control according to the following formula: $\mathrm{IP}=[(d \mathrm{c}-d \mathrm{t}) / d \mathrm{c}] \times$ 100. Where: (IP) is the inhibitory percentage, (dc) is the mycelium diameter in the control petri dish, and (dt) is the mycelium diameter in the natural extracts treated petri dish.

\section{RESULTS AND DISCUSSION}

\section{Phytochemical constituents of extract}

The results of chemical analysis for the studied extract of $A$. nilotica pods revealed that the presence of phytochemicals constituent groups such as alkaloids, terpenoids, flavonoids, tannins and steroids, while saponins was absent. This finding is in agreement with many of the previous studies; e.g., Seigler (2003), Jigam et al., (2010), Malviya et al., (2011), Abdul-Wadood et al., (2013), Sarkiyayi and Abdul Rasheed (2013), Auwal et al.,(2014) and Bwai et al., (2015).

All, in general, reported that a number of secondary metabolites including alkaloids, terpenes, flavonoids and tannins were identified in the extract of various Acacia species. Gas chromatography-mass spectroscopy (GCMS) analysis

The common identified compounds by GC-MS analysis in the different fractions of the A. nilotica pods extract listed in Table (1) were as follows: Piperitone, elemol, ethyl palmitate, stigmasterol, heptacosane, palmitic acid, tetradecanoic acid, ethyl gallate, campesterol, octadecanoic acid, hexadecanoic acid, gallic acid, $\beta$ sitosterol, pyrogallol, pyrocatechol, guanosine, desul phosinigrin, $\beta$-eudesmol, ethyl iso-allocholate and estradiol, 3-deoxy. 
Table 1. Identified compounds in the fractions of $\boldsymbol{A}$. nilotica pods extract.

\begin{tabular}{lccc}
\hline Fractions & Eluting solvents system & Identified compounds & Chemical group \\
\hline $\mathrm{F}_{1}$ & n-hexane; $100 \%$ & Piperitone - Elemol & Terpenoids \\
$\mathrm{F}_{2}$ & n-hexane; ethyl acetate; & Ethyl palmitate & Terpenoids \\
& $50: 50 \%$ & Stigmasterol & Teroids \\
$\mathrm{F}_{3}$ & n-hexane: ethyl acetate; & Heptacosane - Palmitic acid- Tetradecanoic acid & Tannin \\
& $25: 75 \%$ & Ethyl gallate & Steroids \\
$\mathrm{F}_{4}$ & Ethyl acetate; $100 \%$ & Campesterol - Octadecanoic acid & Terpenoids \\
& & Hexadecanoic acid & Tannin \\
$\mathrm{F}_{5}$ & Ethyl acetate: methanol; & Gallic acid & Steroids \\
$\mathrm{F}_{6}$ & $50: 50 \%$ & $\beta$-Sitosterol & Tannin \\
& Ethyl acetate: methanol; & Pyrogallol - Pyrocatechol & Alkaloids \\
$\mathrm{F}_{7}$ & $25: 75 \%$ & Guanosine & Alkaloids \\
\hline
\end{tabular}

It was noticed that each fraction contain a major of certain compounds differ than other fractions based on partitioning (or polarity) of the extract components under different solute systems.

As the present study, many of the similar previous researches e.g., Singh et al., (2010) and Malviya et al., (2011) identified variety of phytochemical compounds of the essential oil extracted from different plants including $A$. nilotica. The variability in active compounds and their concentrations in the $A$. nilotica extract is expected to affect in the biological activities against different pests.

Insecticidal effects of treatment

Egg stage of $\boldsymbol{C}$. capitata and $\boldsymbol{B}$. zonata

Table (2) shows some differences in the egg hatchability between $C$. Capitata and B. zonata, and illustrates the ovicidal activity of $A$. nilotica extract by explain the percentage of the egg hatch for both insects with different concentrations of extract $(0,200,400,700$, 800 and 1000 ppm).

The results show that the egg hatchability percentages of C. Capitata and B. zonata were decreased gradually, and averaged at 26.1 and $33.3 \%$, respectively.

In general, it is clear that the $C$. Capitata eggs more susceptible for $A$. nilotica extract levels than B. zonata.
Table 2. Effects of the tested extract of $A$. nilotica pods on egg hatchability for both $C$. Capitata and $B$. zonata.

\begin{tabular}{lcc}
\hline A. nilotica extract & \multicolumn{2}{c}{ \% Egg hatchability (Mean \pm SE) } \\
\cline { 2 - 3 } concentration $(\mathbf{p p m})$ & C. Capitata & B. zonata \\
\hline 0.0 & $80.0 \pm 1.9$ & $80.0 \pm 1.3$ \\
200 & $70.0 \pm 1.8$ & $76.7 \pm 3.3$ \\
400 & $53.3 \pm 2.5$ & $70.0 \pm 4.1$ \\
700 & $40.0 \pm 1.3$ & $53.3 \pm 2.6$ \\
800 & $13.3 \pm 1.6$ & $20.0 \pm 1.3$ \\
1000 & $0 \pm 0$ & $0 \pm 0$ \\
Average (\%) & 26.1 & 33.3 \\
\hline
\end{tabular}

Larvae stage of $C$. capitata and $B$. zonata

The knockdown effect of the extract was tested for larvae of $C$. capitata and B. zonata in separate bioassay experiments. The results presented in Tables ( 3 and 4 ) shows that the percentage of larval mortality was increased in relation to the concentration and exposure period in all cases as compared to the untreated group, where the percentage of larval mortality was $3.33 \%$ at $200 \mathrm{ppm}$ and $100 \%$ at 1000 ppm of $A$. nilotica extract after $48 \mathrm{hrs}$ and $72 \mathrm{hrs}$ exposure periods, respectively.

Table 3. Larvicidal effect of different concentrations of $\boldsymbol{A}$. nilotica pods extract on larvae of $\boldsymbol{C}$. Capitata.

\begin{tabular}{|c|c|c|c|c|c|c|c|c|c|c|}
\hline \multirow{2}{*}{$\begin{array}{l}\text { A. nilotica } \\
\text { extract conc. } \\
\text { (ppm) }\end{array}$} & \multicolumn{10}{|c|}{ Mortality percentages (\%) at different times } \\
\hline & 12 hrs. & 24 hrs. & 48 hrs. & 72 hrs. & 4 days & 5 days & 6 days & 7 days & 8 days & 9 days \\
\hline Control (0.0) & 0 & 0 & 0 & 0 & 0 & 0 & 3.33 & 0 & 6.66 & 0 \\
\hline 200 & 0 & 0 & 3.33 & 10 & 26.7 & 36.7 & 56.7 & 80 & 93.3 & 100 \\
\hline 300 & 0 & 0 & 3.33 & 13.3 & 26.6 & 53.3 & 73.3 & 100 & 0 & 0 \\
\hline 500 & 0 & 10 & 20 & 40 & 66.7 & 86.7 & 100 & 0 & 0 & 0 \\
\hline 750 & 16.7 & 40 & 56.7 & 83.3 & 100 & 0 & 0 & 0 & 0 & 0 \\
\hline 1000 & 26.6 & 50 & 76.6 & 100 & 0 & 0 & 0 & 0 & 0 & 0 \\
\hline
\end{tabular}

Table 4. $\mathrm{LC}_{50}$ values and their $\mathbf{9 5 \%}$ confidence limits for larvae of $C$. Capitata exposed to $A$. nilotica pods extract.

\begin{tabular}{lcccc}
\hline $\begin{array}{l}\text { parameters } \\
\text { Exposure } \\
\text { period }\end{array}$ & $\begin{array}{c}\mathbf{L C}_{\mathbf{5 0}} \text { of } \\
\text { A. } \text { nilotica } \\
\text { extract } \mathbf{( p p m )}\end{array}$ & $\begin{array}{c}\text { 95\% Confidence of } \\
\text { Lower }- \text { Upper } \\
\text { Limits } \mathbf{( p p m )}\end{array}$ & $\begin{array}{c}\text { Slope } \\
\pm\end{array}$ \\
\hline $48 \mathrm{hrs}$ & 714.1 & 1263.1 & 1874.6 & $5.24 \pm 0.7$ \\
$72 \mathrm{hrs}$ & 504.4 & - & - & $1.93 \pm 0.2$ \\
4 days & 389.8 & - & - & $2.78 \pm 0.5$ \\
5 days & 261.1 & 600.8 & 1072.0 & $3.61 \pm 0.5$ \\
\hline
\end{tabular}

Moreover, the toxicity of the essential oil against larvae of $C$. capitata showed that the $\mathrm{LC}_{50}$ were; 714.1, 504.4, 389.8 and 261.1 ppm, respectively.

The observations during the experiment appeared the larval period and total development period were found to be prolonged with the tested extract of $A$. nilotica.

Concerning the larvae stage of B.zonata, tables 5 and 6 illustrates that the larvicidal activities of the tested $A$. nilotica pods extract on larvae of B.zonata through $\mathrm{LC}_{50}$ 
were; 792.7, 551.8, 372.4 and 278 ppm after exposure times of 48 hrs., 72 hrs., 4 days and 5 days, respectively.

Where the lowest concentration; 200 ppm caused approximately $6.67 \%$ mortality in larvae insect population after $72 \mathrm{hrs}$ compared to $100 \%$ mortality at the highest concentration (1000 ppm) after the same period.

Table 5. Effects of the tested extract of $\boldsymbol{A}$. nilotica pods on larvae of $\boldsymbol{B}$.zonata.

\begin{tabular}{lccccccccccc}
\hline $\begin{array}{c}\text { A. nilotica extract } \\
\text { conc. (ppm) }\end{array}$ & $\begin{array}{c}\mathbf{1 2} \\
\text { hrs. }\end{array}$ & $\begin{array}{c}\mathbf{2 4} \\
\text { hrs. }\end{array}$ & $\begin{array}{c}\mathbf{4 8} \\
\text { hrs. }\end{array}$ & $\begin{array}{c}\mathbf{7 2} \\
\text { hrs. }\end{array}$ & $\begin{array}{c}\mathbf{4} \\
\text { days }\end{array}$ & $\begin{array}{c}\mathbf{5} \\
\text { days }\end{array}$ & $\begin{array}{c}\mathbf{6} \\
\text { days }\end{array}$ & $\begin{array}{c}\mathbf{7} \\
\text { days }\end{array}$ & $\begin{array}{c}\mathbf{8} \\
\text { days }\end{array}$ & $\begin{array}{c}\mathbf{9} \\
\text { days }\end{array}$ \\
\hline Control (0.0) & 0 & 0 & 0 & 0 & 0 & 0 & 0 & 0 & 0 & 0 \\
200 & 0 & 0 & 0 & 6.67 & 20 & 30 & 46.7 & 73.3 & 90 & 100 \\
300 & 0 & 0 & 0 & 6.67 & 23.3 & 46.7 & 70 & 96.7 & 100 & 0 \\
500 & 0 & 10 & 20 & 46.7 & 73.3 & 100 & 0 & 0 & 0 & 0 \\
750 & 13.3 & 33.3 & 50 & 63.3 & 90 & 100 & 0 & 0 & 0 & 0 \\
1000 & 13.3 & 40 & 63.3 & 100 & 0 & 0 & 0 & 0 & 0 & 0 \\
\hline
\end{tabular}

Table 6. $\mathrm{LC}_{50}$ values and their $95 \%$ confidence limits for larvae of $B$. zonata exposed to $A$. nilotica pods extract.

\begin{tabular}{|c|c|c|c|}
\hline $\begin{array}{l}\text { parameters } \\
\text { Exposure } \\
\text { period }\end{array}$ & $\begin{array}{l}\mathbf{L C}_{50} \text { of } \\
\text { A. nilotica } \\
\text { extract } \\
\text { (ppm) }\end{array}$ & $\begin{array}{l}\text { 95\% Confidence } \\
\text { of } \\
\text { Lower - Upper } \\
\text { Limits (ppm) }\end{array}$ & $\begin{array}{c}\text { Slope } \\
\pm \\
\text { SE }\end{array}$ \\
\hline $48 \mathrm{hrs}$ & 792.7 & $1596.8 \quad 3354.11$ & $3.95 \pm 0.63$ \\
\hline $72 \mathrm{hrs}$ & 551.8 & $-\quad \quad-$ & $5.52 \pm 0.70$ \\
\hline 4 days & 372.4 & - & $4.04 \pm 0.36$ \\
\hline 5 days & 278 & - & $3.61 \pm 0.50$ \\
\hline
\end{tabular}

\section{Adult stage of $\boldsymbol{C}$. capitata and $\boldsymbol{B}$. zonata}

Results listed in tables 7 and 8 shows that the percentage of adult mortality was increased with increasing the concentration and the time of exposure compared with the untreated control. The tested plant extract have promising repellent activity against tested insects. Results demonstrate the percentage of adult $C$. capitata mortality with time after exposure to different concentration of A.nilotica essential oil. Results revealed that this oil at lowest concentration $100 \mathrm{ppm}$ caused approximately 3.33 $\%$ mortality in adult insect population after $12 \mathrm{hrs}$ compared to $100 \%$ mortality at the highest concentration of $500 \mathrm{ppm}$ after $48 \mathrm{hrs}$. The insecticidal activity of the essential oil of A.nilotica was evaluated on the basis of mortality percentages and the estimated $\mathrm{LC}_{50}$ values of $A$. nilotica pods extract. It was decreased from 1253 to 255 to 131 and to $84 \mathrm{ppm}$ with increasing of $C$. capitata exposure periods; 24, 36, 48 and $60 \mathrm{hrs}$, respectively, indicating that this extract has a promising insecticidal activity.

Table 7. Effects of the tested extract of A.nilotica pods on adult of $\boldsymbol{C}$. capitata.

\begin{tabular}{lccccccccc}
\hline $\begin{array}{l}\text { A. nilotica extract } \\
\text { conc. }(\mathbf{p p m})\end{array}$ & \multicolumn{8}{c}{ Mortality percentages (\%) at different times } \\
\cline { 2 - 10 } Control (0.0) & $\mathbf{3}$ hrs. & $\mathbf{6}$ hrs. & $\mathbf{1 2}$ hrs. & $\mathbf{2 4}$ hrs. & $\mathbf{3 6}$ hrs. & $\mathbf{4 8}$ hrs. & $\mathbf{6 0}$ hrs. & $\mathbf{7 2}$ hrs. & $\mathbf{5}$ days \\
100 & 0 & 0 & 0 & 0 & 0 & 3.33 & 0 & 0 & 6.67 \\
200 & 0 & 0 & 3.33 & 16.7 & 26.7 & 43.3 & 56.7 & 79.9 & 100 \\
300 & 3.33 & 10 & 16.7 & 33.3 & 50 & 63.3 & 66.7 & 86.7 & 100 \\
400 & 0 & 3.33 & 6.6 & 26.6 & 50 & 60 & 83.3 & 100 & 0 \\
500 & 0 & 3.33 & 10 & 26.6 & 50 & 73.3 & 100 & 0 & 0 \\
\hline
\end{tabular}

Table 8. $\mathrm{LC}_{50}$ values and their $95 \%$ confidence limits for adults of $C$. capitata exposed to $A$. nilotica pods extract.

\begin{tabular}{lcccc}
\hline $\begin{array}{l}\text { parameters } \\
\text { Exposure } \\
\text { period }\end{array}$ & $\begin{array}{c}\mathbf{L C}_{\mathbf{5 0}} \text { of } \\
\text { A. nilotica } \\
\text { extract(ppm) }\end{array}$ & $\begin{array}{c}\mathbf{9 5 \%} \text { Confidence of } \\
\text { Lower - Upper } \\
\text { Limits (ppm) }\end{array}$ & $\begin{array}{c}\text { Slope } \\
\pm\end{array}$ \\
\hline $4 \mathrm{hrs}$ & 1253 & - & - & $0.8133 \pm 0.25$ \\
$36 \mathrm{hrs}$ & 255 & - & - & $1.485 \pm 0.238$ \\
$48 \mathrm{hrs}$ & 131 & 1394.77 & 50215.78 & $1.148 \pm 0.283$ \\
$60 \mathrm{hrs}$ & 84 & 540.03 & 5790.87 & $1.532 \pm 0.389$ \\
\hline
\end{tabular}

The insecticidal activity of the essential oil of A.nilotica was also tested with respected to adults of B. zonata. The percentage of observed mortality was illustrated in tables 9 and 10 .

The results show toxic efficacy of essential oil to the adults of B. zonata and also have repellent activity, so, it has been added buminal as food attractant. The percentage mortality of $B$. zonata adults increased by increasing the time of exposure and the concentration of the $A$. nilotica pods extract.

Where the lowest mortality was $6.7 \%$ after $12 \mathrm{hrs}$ at the concentration of $100 \mathrm{ppm}$, while the adult's mortality reached to $100 \%$ after $60 \mathrm{hrs}$, with the highest concentration at $500 \mathrm{ppm}$. Furthermore, the results indicated that the essential oil derived from pods of the experimental tree; $A$. nilotica possesses insecticidal activity against both insect pests, but the adults of $C$. Capitata was noticed as more susceptible than of $B$. zonata.

The results of this study are in agreement with Kamaraj et al., (2011) who evaluated the larvicidal and repellent activities of ethyl acetate extracts of the seeds of Acacia concinna against larvae of Anopheles stephensi and Culex quinquefasciatus at five concentrations; 31.25, $62.50,125.00,250.00$, and $500.00 \mathrm{ppm}$ under the laboratory conditions. Results revealed that the plant extract showed repellent properties and moderate larvicidal effects after $24 \mathrm{~h}$ and $48 \mathrm{~h}$ of exposure at $500 \mathrm{ppm}$ of the seed extract. 
Table 9. Effects of the tested $\boldsymbol{A}$. nilotica pods extract on adult of $\boldsymbol{B}$. zonata.

\begin{tabular}{|c|c|c|c|c|c|c|c|}
\hline \multirow{2}{*}{\multicolumn{2}{|c|}{$\begin{array}{l}\text { A. nilotica extract } \\
\text { Conc. }(\mathrm{ppm})\end{array}$}} & \multicolumn{6}{|c|}{ Mortality } \\
\hline & & \multicolumn{2}{|c|}{3 hrs. } & 6 hrs. & \multicolumn{2}{|c|}{12 hrs. } & 24 \\
\hline \multicolumn{2}{|c|}{ Control (0.0) } & \multicolumn{2}{|l|}{0} & 0 & \multicolumn{2}{|c|}{3.33} & \\
\hline 100 & & \multicolumn{2}{|l|}{0} & 0 & \multicolumn{2}{|c|}{6.7} & \\
\hline 200 & & \multicolumn{2}{|l|}{0} & 6.7 & \multicolumn{2}{|c|}{10} & \\
\hline 300 & & \multicolumn{2}{|l|}{0} & 0 & \multicolumn{2}{|c|}{10} & \\
\hline 400 & & \multicolumn{2}{|l|}{0} & 3.33 & \multicolumn{2}{|c|}{20} & \\
\hline 500 & & \multicolumn{2}{|c|}{6.7} & 20 & \multicolumn{2}{|c|}{26.7} & \\
\hline \multicolumn{8}{|c|}{$\begin{array}{l}\text { Table 10. } \mathrm{LC}_{50} \text { values and their } 95 \% \text { confidence limits } \\
\text { for adults of } B \text {. zonata exposed to } \text { A. nilotica } \\
\text { extract. }\end{array}$} \\
\hline $\begin{array}{l}\text { parameters } \\
\text { Exposure } \\
\text { period }\end{array}$ & \multicolumn{2}{|c|}{$\begin{array}{c}\mathrm{LC}_{50} \text { of } \\
\text { A. nilotica } \\
\text { extract(ppm) }\end{array}$} & \multicolumn{3}{|c|}{$\begin{array}{l}\text { 95\% Confidence } \\
\text { of Lower - Upper } \\
\text { Limits (ppm) } \\
\end{array}$} & \multicolumn{2}{|c|}{$\begin{array}{l}\text { Slope } \\
\pm \\
\text { SE } \\
\end{array}$} \\
\hline $24 \mathrm{hrs}$ & \multicolumn{2}{|c|}{567.62} & - & & \multicolumn{3}{|c|}{$1.690 \pm 0.270$} \\
\hline $36 \mathrm{hrs}$ & \multicolumn{2}{|c|}{327.89} & - & & \multicolumn{3}{|c|}{$2.19 \pm 0.262$} \\
\hline $48 \mathrm{hrs}$ & \multicolumn{2}{|c|}{191.40} & - & - & \multicolumn{3}{|c|}{$1.93 \pm 0.244$} \\
\hline $60 \mathrm{hrs}$ & \multicolumn{2}{|c|}{131.28} & 517.01 & & & \multicolumn{2}{|c|}{$2.37 \pm 0.272$} \\
\hline
\end{tabular}

The previous similar studies revealed that many of plant extracts has insecticidal, antibacterial, antifungal and antimolluscidal activities, and antioxidant property. From these, Edriss et al., (2012) studied larvicidal effects of three extracts (water, ethanol and petroleum ether) prepared from A. nilotica (leaves and fruits) against Anopheles arabiensis. The results showed that the petroleum ether extracts exerted better mortality effects than other extracts, with fruits treatments being superior to leaves in all cases.

There is correlation between the results of this study and the results obtained by Abdul-lahi et al., (2014). They studied the comparative assessment of the efficacy of A. nilotica bark and root powder on the mortality of Sitophilus zeamais, which is one of the most important pests of maize in storage. Highest mortality of the weevil $(100 \%)$ was observed after $144 \mathrm{~h}$ of treating the maize grain with the highest treatment level $(1.5 \mathrm{~g})$ of both bark and root powders when compared with other treatment levels $(0.5$ and $1.0 \mathrm{~g})$ which recorded $100 \%$ of the weevil only after $168 \mathrm{~h}$ of treatment.

On the other hand, Gautam and Satwinder, (2015) found that the two partitioned fractions viz. ethyl acetate and water of acetone bark extract of $A$. nilotica were tested for their influence on the development of larvae of Spodoptera litura. Both fractions showed a toxic influence on larvae of $S$. litura but the effect was markedly greater with ethyl acetate fraction. The toxic effects were manifested in the form of increased larval mortality, reduced pupal weight, decreased adult emergence and prolongation in larval, pupal and total development period. Fungicidal activity of the $A$. nilotica extract against $A$. flavus fungus growth.

The antifungal efficacy of $A$. nilotica essential oil against pathogenic fungi of $A$. flavus and $S$. sclerotiorum was carried out under In vitro conditions. The obtained results showed in Figure (1) revealed effective inhibitor of A. nilotica pods against the tested pathogenic fungi. The antifungal efficacy of ethanolic extract causes weak effective of growth inhibition at percentage ranging from 4.05 to $37.48 \%$ when the concentration increased from 100 to $1000 \mathrm{ppm}$, respectively.

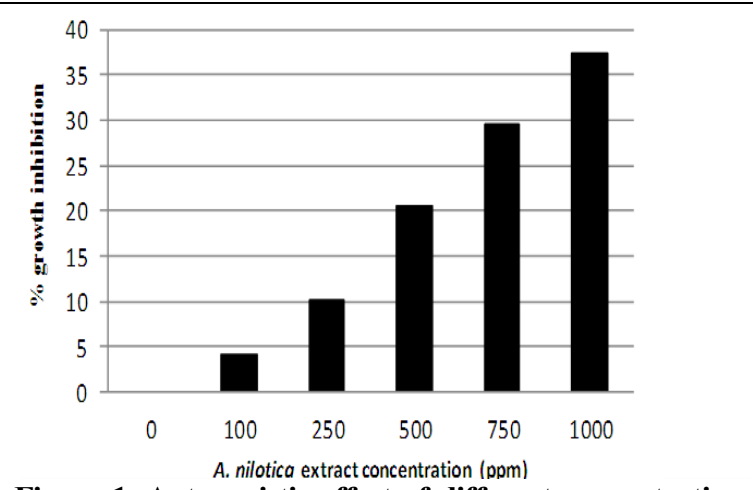

Figure 1. Antagonistic effect of different concentrations of $A$. nilotica extract on $A$. flavus fungus growth

Fungicidal activity of the $A$. nilotica extract Against $S$. sclerotiorum fungus growth

Figure (2) illustrates the inhibition activity of essential oil of $A$. nilotica with different tested concentrations for growth of mycelium $S$. sclerotiorum. The extract from the tested tree pods possess antifungal activity against growth of the tested fungal strain at various concentrations. The minimum inhibitory concentration (100 ppm) of $A$. nilotica extract causes $13.85 \%$ of inhibition, while $1000 \mathrm{ppm}$ as maximum of extract inhibit $60 \%$ of the mycelium S. sclerotiorum growth.

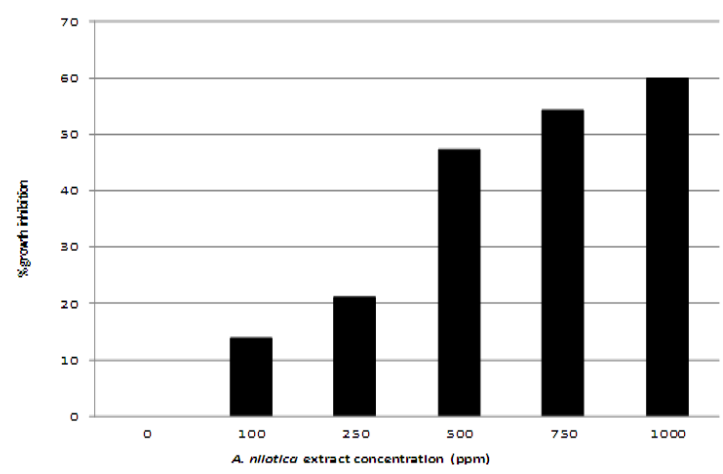

Figure 2. Antagonistic effect of different concentrations of $A$. nilotica extract on $S$. sclerotiorum fungus growth

These results are in agreement with many of the previous researches, e.g., Mahesh and Satish, (2008). They revealed that the bark and leaf methanolic extracts of $A$. nilotica showed significant antifungal activity against $A$. flavus when compared with the root extract. Mohana et al., (2011) showed significant antifungal activity of methanol extract of fresh leaves of $A$. nilotica $s p$. against pathogenic fungal species; A. flavus tested in vitro. Moreover, Prabhahar et al., (2012) resulted that the ethanol extract of 
A. nilotica was more fungal inhibitory activity when compared to ethyl acetate extract against Aspergillus flavus followed by Aspergillus fumigatus. On the other hand, Rathod and Pawar, (2012) explained that the plant extracts of Azadirachta indica A. Juss and Acacia nilotica (L.) showed inhibitory effect on linear growth of species of fungi belonging Aspergillus flavus, Aspergillus fumigatus, and Penicillium chrysogenum. The results of Abdul Rahman et al., (2014) are confirm the obtained results in the present study. They indicated that the ethanolic and chloroform extracts of $A$. nilotica $L$. cause 4.91 and $7.0 \%$ growth inhibition against $A$.niger, whereas at $4.61 \%$ and $10.9 \%$ growth inhibition against A. flavus fungi. Also, Bwai et al., (2015) showed an increase in the zone of growth inhibition of Aspergillus niger, Aspergillus flavon, and Fusarium oxyfurum with increasing the concentration of the A. nilotica fruit ethanol extract. The present study recommend that the phytochemical compounds identified in the tested pods of Acacia nilotica are important and have commercial interest to pesticide formulation companies towards the possibilities for replacing the synthetic chemicals by natural products as botanical pesticides for treatment of various crop pests for achieving more safe food for humans and protect our environment.

\section{REFERENCES}

Abdul Rahman, A., Abdul Shakoor, Zaib, G., Mumtaz, A.S., hesham, Y. and Abdul Aziz, N. (2014). Comparative antimicrobial activity of Acacia nilotica L. leaves extracts against pathogenic bacteria and fungi. Journal of Medicinal Plant Research, 8(29): 975-982

Abdul-lahi, N., Umar,I ., Tukur, Z. and Babura, S. R.,(2014). Comparative efficacy of the bark and root powders of Acacia nilotica against maize weevil Sitophilus zeamais (Motsculsky) (Coleoptera :Curculionidae) in Kano State of Nigeria. African Journal of Agricultural Research. 9(6) :588 - 592

Abdul-Wadood, Mehreen, G., Syed, B. J., Muhammad, N., Ajmal, K., Rukhsana, G. and Asnad, (2013). Phytochemical Analysis of Medicinal Plants Occurring in Local Area of Mardan. Biochem Anal Biochem., (2): 2-4

Auwal, M. S., Saka, S., Mairiga, I. A., Sanda, K.A., Shuaibu, A., Ibrahim, A.(2014). Preliminary phytochemical and elemental analysis of aqueous and fractionated pod extracts of Acacia nilotica (Thorn mimosa). Veterinary Research Forum; 5 (2):95-100

Bwai, M.D., Uzama, D., Abubakar, S., Olajide,O.O. Ikokoh,P.P. Magu. J., (2015). Proximate, elemental, phytochemical and anti-fungal analysis of Acacia nilotica fruit. Pharmaceutical and Biological Evaluations, 2 (3): 52-59.

Cohen, H and Yuval, B (2000). Perimeter Trapping Strategy to Reduce Mediterranean fruit fly (Diptera: Tephritidae) Damage on Different Host Species in Israel. J.Econ. Entomol. 93(3): 721-725

Davar, R., Darvishzadeh, R., and Majd, A. (2013). Changes in antioxidant systems in sunflower partial resistant and susceptible lines as affected by Sclerotinia sclerotiorum. Biologia., 68(5): 821-829
Edriss, A. E., Abdalla, A. S., and Zuhair, A. A., (2012). Preliminary studies on phytochemicals and larvicidal effects of Acacia nilotica L. extracts against Anopheles arabiensis Patton. Scientific Research and Essays, 7(50):4253-4258

Gautam, S. and Satwinder, K.S (2015). Influence of partially purified fractions of acetone extract of Acacia nilotica (L.) on development of Spodoptera litura (Fab.). International Journal of Advanced Research, 2 (3):1008-1012

Gurjar, M. S., Shahid, A., Masood, A. and Kangabam, S. S., (2012). Efficacy of plant extracts in plant disease management. Agricultural Sciences, 3(3):425-433

Javeria, S., Kumar, H., Gangwar, R. K., Tyagi, S. and Yadav, R. S. (2014). Isolation of Stem rot Disease Causing Organism of Brinjal and their in-vitro Inhibition with Fungicides and Bio-control Agents, 83(9-2):1662-1670

Jebasingh , E. J. Rajesh, R.P., and Lakshmikandan, M. (2011). Antibacterial activity of seaweed ulvalactuca against fish pathogens isolated from marine fish katsuwonus pelamis . International Journal of Pharmacy \& Technology. 3 (2):2306-2314

Jigam, A.A., Akanya, H.O., Dauda, B.E. and Okogun, J.O., (2010). Polygalloyl tannin isolated from the roots of Acacia nilotica Del. (Leguminoseae) is effective against Plasmodium berghei in mice. J. Med. Plants Res., 4(12): 1169-1175.

Kamaraj, C., Abdul Rahuman, Asokan, B., Gandhi, E., Abdul Abduz, Z., and Thirunavukkarasu, S., (2011). Larvicidal and repellent activity of medicinal plant extracts from Eastern Ghats of South India against malaria and filariasis vectors. Asian Pacific Journal of Tropical Medicine, 698-705

Mahesh, B. and Satish, S., (2008). Medicinal Plant against Plant and Human Pathogens. World Journal of Agricultural Sciences, 4 (5): 839-843.

Mahmoud, M.F., (2014). New indices for measuring some quality control parameters of the Mediterranean fruit fly, Ceratitis capitata (Wied.). Arthropods, 3(1): 88-95

Malviya, S., Swati, R., Anil, K. and Meena, V., (2011). Medicinal attributes of Acacia nilotica Linn. A comprehensive review on ethnopharmacological claims. International Journal of Pharmacy \& Life Sciences. Int. J. of Pharm. \& Life Sci., 6(2):830-837

Mbatchou, V.C., Ayebila, A.J and Apea, O.B. (2011). Antibacterial activity of phytochemicals from Acacia nilotica, Entada africana and Mimosa pigra L. on Salmonella typhi. Journal of Animal \& Plant Sciences, 10(1): 1248-1258

Mohan, M., Haider, S. Z., Andola, H. C. and Purohit, V. K. (2011). Essential Oils as Green Pesticides: For Sustainable Agriculture. Journal of Pharmaceutical, Biological and Chemical Sciences. 2 (4):100-106

Mohana, D. C., Prasad, P., Vijaykumar, V.and Raveesha, K. A., (2011). Plant extract effect on seed-borne pathogenic fungi from seeds of paddy grown in Southern India. Journal of Plant Protection Research. 2(51): 101- 106 
Perrone, G., Susca1, A., Cozzi, G., Ehrlich, K., Varga, J., Frisvad, J.C., Meijer, M., Noonim, P., Mahakarnchanaku, W. and Samson, R.A. (2007). Biodiversity of Aspergillus species in some important agricultural products. Studies in Mycology (59): 53-66

Prabhahar. C., Saleshrani, K., Saranraj, P and Tharmaraj, K., (2012). Studies on the antifungal activity of Turnera subulata and Acacia nilotica against pathogenic fungal pathogens. International Journal of Recent Scientific Research. 3(3):149 -154

Rathod, L. R. and Pawar, P. V. (2012). Antimicrobial activity of medicinal plant to control seed borne pathogen of soybean. Current Botany, 3(2): 10-12

Sarkiyayi, S. and Abdul Rasheed, K., (2013). Properties of Acacia Nilotica leaf extract: A preliminary investigation on anti-typhoid. International Journal of Current Biochemistry Research, 1(2): 9- 14
Sarwar, M., Hamed, M., Rasool, B., Yousaf, M. and Hussain, M (2013). Host Preference and Performance of Fruit Flies Bactrocera zonata (Saunders) and Bactrocera cucurbitae (Coquillett) (Diptera: Tephritidae) For Various Fruits and Vegetables. International Journal of Scientific Research in Environmental Sciences (IJSRES), 1(8):188-194

Seigler, D.S. (2003). Phytochemistry of Acacia sensu lato. Biochemical Systematics and Ecology, (31): 845873

Singh, R., Singh, B., Singh, S., Kumar, N., Kumar, S. and Arora, S. (2010). Umbelliferone - An antioxidant isolated from Acacia nilotica (L.) Willd. Ex. Del. Food Chem., 120: 825-830

\footnotetext{
تقييم فعالية مستخلص قرون أشجار القرض كمبيدات حيوية حشرية وفطرية

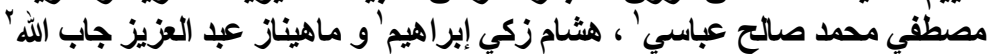

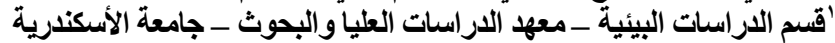

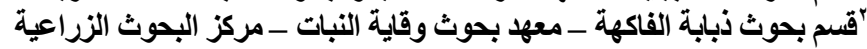

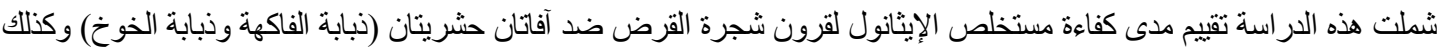

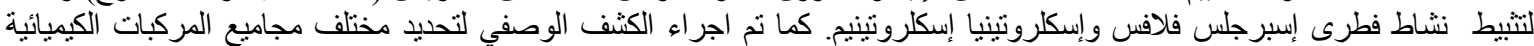

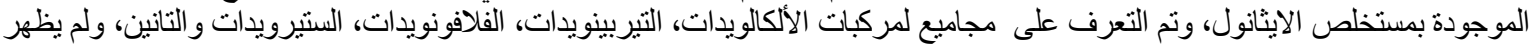

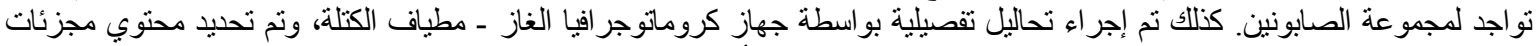

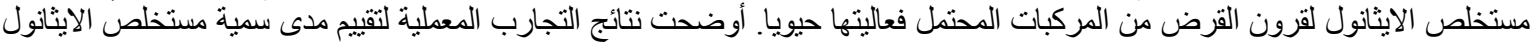

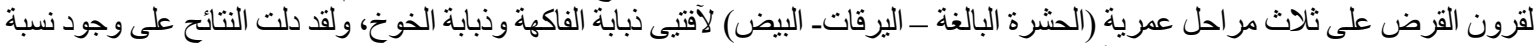

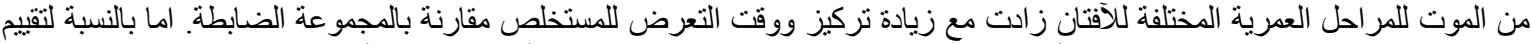

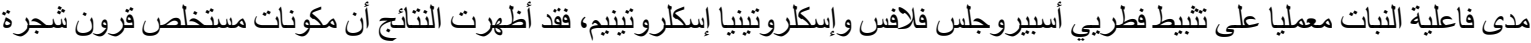
القرض تمنللك فاعلية ملحوظة مضات معليادة لنمو الفطريات المختبرة.
} 